\title{
Thermoluminiscence Response of an Alloy Quaternary Ionic Crystal Exposed to High Energy Radiation
}

\author{
Ricardo Rodriguez-Mijangos ${ }^{1}$, R. Pérez-Salas ${ }^{1}$, M. Cervantes $^{1}$ and A. Rodriguez-Soria ${ }^{2}$ \\ 1. Departamento de Investigación en Física, Universidad de Sonora, P. O. Box 5-88, 83190, Hermosillo, Sonora, Mexico \\ 2. División de Ciencias Básicas e Ingeniería Av. San Pablo No. 180, UAM Azcapotzalco, Col. Reynosa Tamaulipas, C.P. 02200, \\ México D. F. Mexico
}

Received: April 12, 2016 /Accepted: April 25, 2016 /Published: July 31, 2016.

\begin{abstract}
Abstact: The alkali halide crystals exhibit significant TL (thermoluminescence) properties when exposed to ionizing radiation. The defects in crystals can be produced in high concentration by means of chemical impurities, radiation, mechanical work and others processes. This study is concerned with the TL properties of quaternary mixtures of alkali halide crystals when they are irradiated with beta and gamma-rays. The samples were made mixing $\mathrm{KCl}, \mathrm{KBr}, \mathrm{RbCl}, \mathrm{RbBr}$ salts doped with divalent europium $\left(\mathrm{Eu}^{2+}\right)$, by the Czochralski method sintering at $400{ }^{\circ} \mathrm{C}$ during 6 hours in a $\mathrm{N}_{2}$ atmosphere. The samples were exposed to beta and gamma rays. We present the TL glow curves, demonstrating that the nature of the defects in the crystals can be produced by trapping states and recombination mechanisms. The highest temperature TL curves are the most interesting due to possible applications in dosimetry and optical energy storage.
\end{abstract}

Key words: Materials irradiation, alkali halide mixed crystals, beta and gamma radiation, optical energy storage.

\section{Introduction}

Early works [1] report TL (thermoluminescence) studies in insulators showing the effect of ionizing radiation in alkali halides single crystals particularly in europium doped alkali halide crystals [2]. More recently, some reports are available about binary crystalline mixtures irradiated with beta rays [3]. A complete characterization of a thermoluminescent material gives a characteristic glow curves related to stability of their traps. Recent studies with mixed ternary crystals indicate that can be useful for dosimetry applications due to the high temperature TL response peaks [4]. The high TL response produced with gamma radiation of ternary and quaternary crystals has been partially studied [5].

In this work we report results of TL of quaternary alkali halide mixture of crystals in equal molar

Corresponding author: Ricardo Rodriguez Mijangos, Ph.D., professor, research fields: optical properties of solids, defects in solids, statistical mechanics. concentration doped with divalent europium subjected to beta and gamma radiation, which exhibited a TL response after being treated with various heat procedures applied to samples prior to irradiation.

We characterized the quaternary crystal by optical spectroscopy to obtain data of possible formation of europium aggregates. TL was performed later with irradiated crystals.

\section{Materials and Method}

The salts $\mathrm{KCl}, \mathrm{KBr}, \mathrm{RbCl}, \mathrm{RbBr}$ were grown by Czochralski technique $\mathrm{EuCl}_{2}(0.1 \%)$ were added to the melt in 0.25 molar fraction portions.

To obtain the spectra of excitation and emission of the quaternary samples we use a spectro-fluorometer.

Samples were heated at $500{ }^{\circ} \mathrm{C}$ and quenched showed fractures, afterwards these were irradiated with a $90 \mathrm{Sr} / Y$ source of beta radiation for a lapse of $5 \mathrm{~s}$ at a rate of approximately $4.9 \mathrm{~Gy} / \mathrm{min}$. TL intensity was measured from low temperature to $673 \mathrm{~K}$ in a RISO TL system. 
Other samples of same type were irradiated with gamma radiation with heat treatments at $573 \mathrm{~K}, 623 \mathrm{~K}$ and $673 \mathrm{~K}$ for equal time periods smaller than one hour to destroy possible Europium agglomerates, and then cooled down at room temperature. Then they were irradiated in equilibrium with $100 \mathrm{mGy}$ of $60 \mathrm{Co}$ gamma radiation. The readings were taken two hours after irradiation. TL analysis of the samples was performed with a 4,000 Harshaw TL reader, coupled to a PC. The TL signal was obtained between $333 \mathrm{~K}$ and $573 \mathrm{~K}$ at a heating rate of $2 \mathrm{~K} / \mathrm{s}$. All readings were carried out under nitrogen atmosphere, to avoid spurious contributions in the luminescent signal.

\section{Results and Discussion}

In Fig. 1 we show the excitation and emission spectra of a quaternary sample doped with europium. Show signals between two europium characteristic peaks [6]. These enable various kinds of traps, probably due to some kind of europium aggregates.

In Fig. 2 we show the TL results with beta radiation. The typical TL emission features are mainly four glow peaks located at $362 \mathrm{~K}, 415 \mathrm{~K}, 491 \mathrm{~K}, 576 \mathrm{~K}$, approximately. The peak emission of TL that occurs around $415 \mathrm{~K}$ attracts the attention because it corresponds to peak of $0.5 \mathrm{Cl}$ and $0.5 \mathrm{Br}$ composition and that responds well to halide composition effect on the TL glow peak temperature of mixed crystals [3].

At temperatures above to $473 \mathrm{~K}$ are two glow peaks that can be related to different types of $\mathrm{F}$ centers or europium aggregates. The low temperature glow peaks give evidence that different traps are present in these composite materials.

For gamma radiation Fig. 3 shows the TL glow curves of a sample for different thermal treatments. Heat treatment given at $573 \mathrm{~K}$ produces a TL glow curve with four peaks at $363,396,435$ and $518 \mathrm{~K}$. With heat treatment increasing $50 \mathrm{~K}$, the TL curve shows four peaks at 363, 398, 426 and $528 \mathrm{~K}$. With heat treatment increasing $100 \mathrm{~K}$, the TL curve showed only one peak at $623 \mathrm{~K}$.

The next step was to give the same heat treatment at $623 \mathrm{~K}$ for 30 minutes, irradiated at the same dose and to take the readings TL 24 and 48 hours after irradiation, Fig. 4 shows the TL curve obtained 48 hours after irradiation and it exhibits the presence of two peaks at $436 \mathrm{~K}$ and $537 \mathrm{~K}$. These were defined as the standard treatment for erasing.

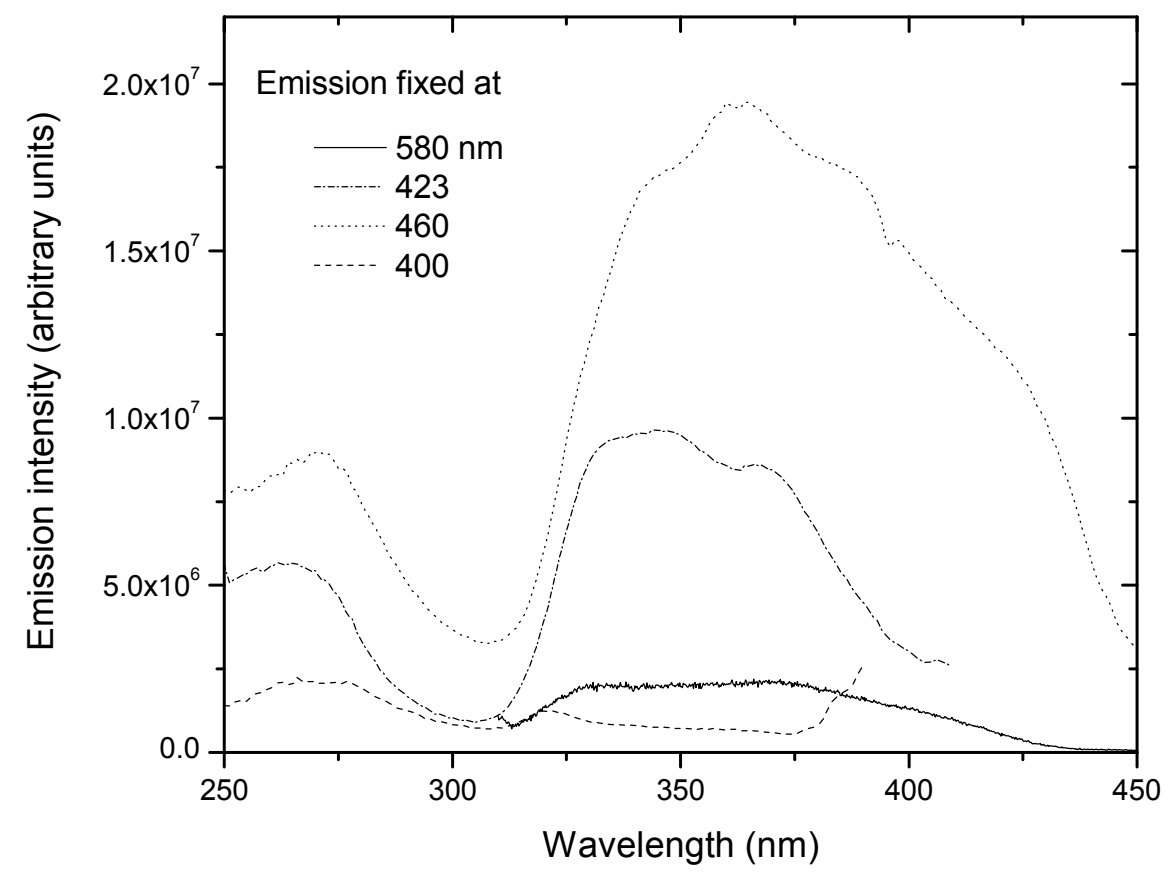

Fig. 1 Excitation spectra of a sample at RT with emissions at (solid) 580, (dash-dot) 423, (dot) 460, (dash) $400 \mathrm{~nm}$. 


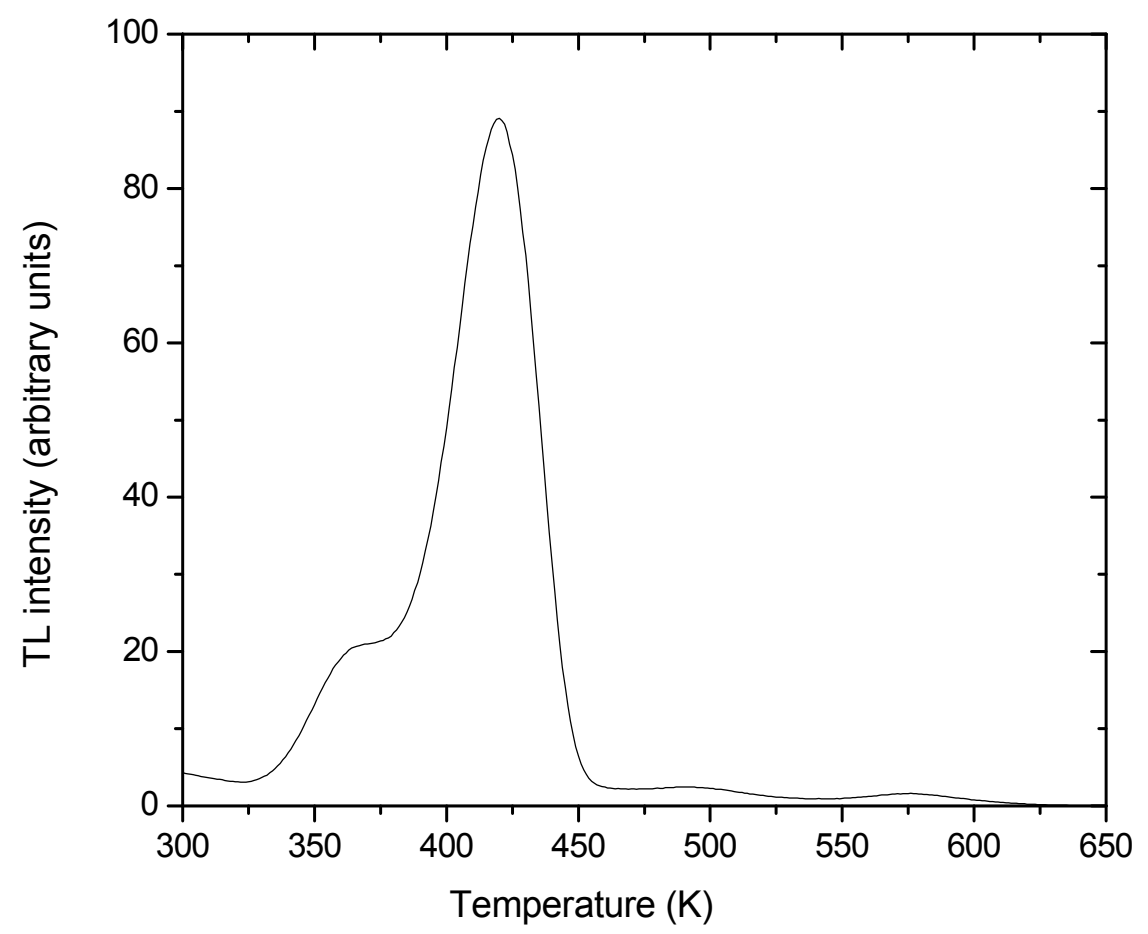

Fig. 2 Glow curve of a thermally treated sample after being exposed to beta ray irradiation.

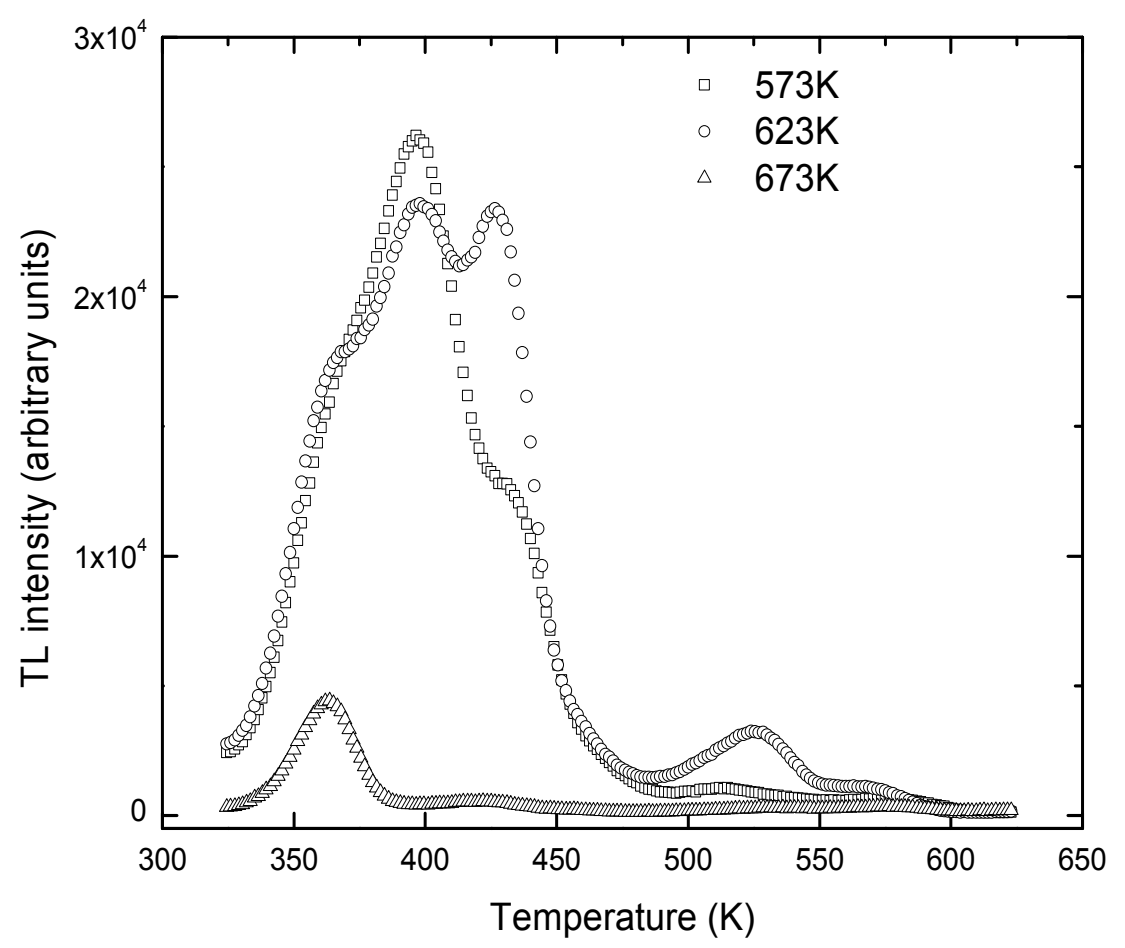

Fig. 3 Glow curves of the irradiated samples subjected to different heat treatments. 


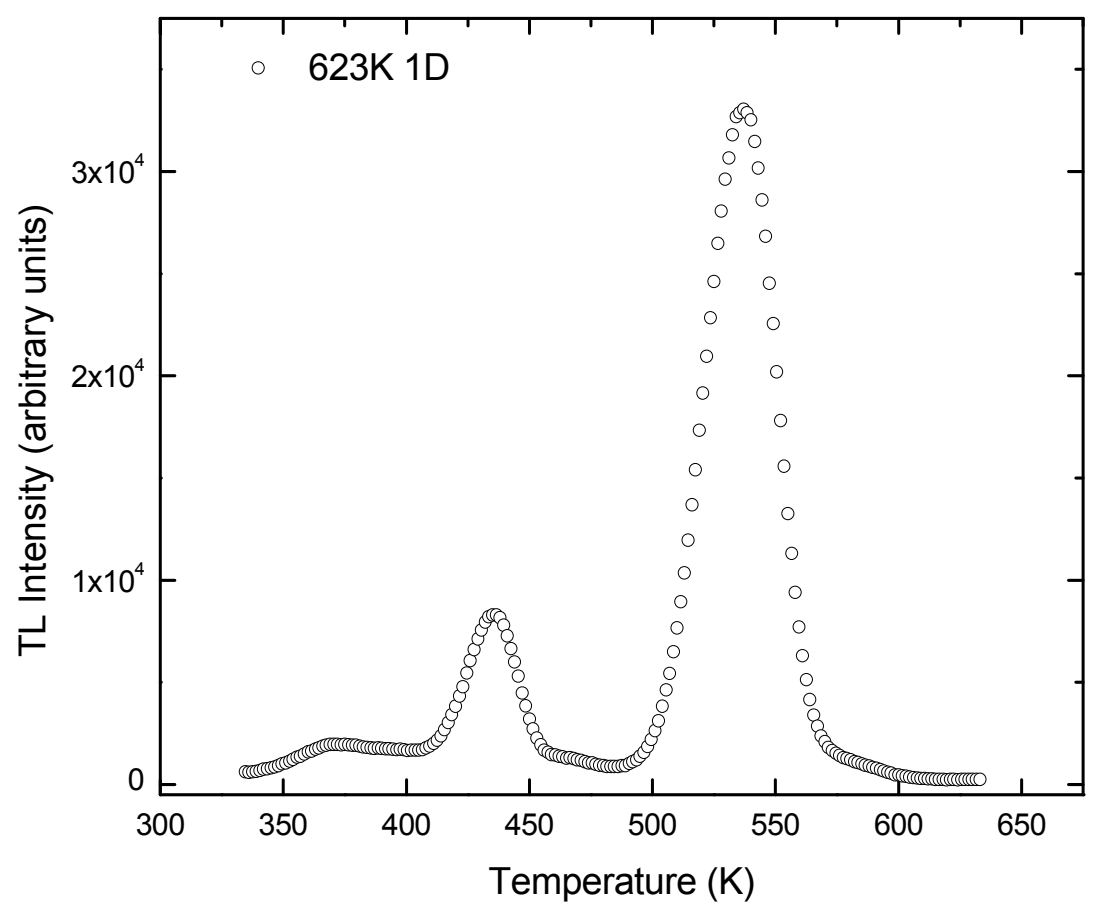

Fig. 4 Thermoluminiscence curve erase heat treated at $623 \mathrm{~K}$, reads 48 hours after radiation.

\section{Conclusions}

We can see in Fig. 2 that low temperature glow peaks associate to beta irradiation match with the peak at $363 \mathrm{~K}$ associated to Fig. 3 for the heat treatment at $673 \mathrm{~K}$, also the other intense peak in Fig. 2 at $426 \mathrm{~K}$ match with a peak appearing with a heat treatment at $623 \mathrm{~K}$. The same peaks obtained with different types of radiation means similar persistent traps.

Seeing the sample as a binary $\mathrm{KBr}_{0.5} \mathrm{KCl}_{0.5}: \mathrm{Eu}^{2+}$ the main glow peaks temperature obeys the molar fraction of halogen composition since it is found in the middle between $\mathrm{KBr}: \mathrm{Eu}^{2+}$ and $\mathrm{RbCl}$ : $\mathrm{Eu}^{2+}$ main glow peaks, while the alkali ions has minor influence in that temperature $[3,7,8]$. TL of four components mixed crystals with several compositions has to be studied to verify the halogen composition dependence of the glow peak temperature.

The possibility of the quaternary crystals as dosimetry or optical energy storage application can be related to persistent traps near to dislocations, because the mixture has very mechanical tensions and many dislocations.

\section{Acknowledgments}

We are grateful to Dr. Pedro Gonzalez for TL characterization support and Dr. Hector Riveros for growing the crystals.

In memorian: G. Vazquez Polo.

\section{References}

[1] McKeever, S. W. 1985. Thermoluminiscence in Solids. Cambridge: Cambridge University Press.

[2] Aceves, R., Perez-Salas, R., and Barboza-Flores, M. 1994. "The Role of F Centers in the Thermoluminescence of Low-Energy UV- and X-irradiated $\mathrm{KCl}: \mathrm{Eu}^{2+}$." Journal of Physics: Condensed Matter 6 (47): 10397-405.

[3] Perez-Salas, R., Aceves, R., Rodríguez-Mijangos, R., Riveros, H. G., and Duarte, C. 2004. "Composition Dependence of Glow Peak Temperature in KCl1-xBrx Doped with Divalent Cations." Journal of Physics: Condensed Matter 16 (3): 491-7.

[4] Rodríguez-Mijangos, R., Perez-Salas, R., and Vazquez-Polo, G. 2006. "Optical Storage on a Dielectric Ternary Crystal Doped with Europium." Optical Materials 28 (12): 1398-400.

[5] Rodríguez Mijangos, R., Vazquez-Polo, G., Perez-Salas, R., and Gonzalez-Martinez, P. 2012. "Therrmoluminescence Response and Its Deconvolution on Crystalline Higher Order Mixtures of Alkali Halides 


\section{Thermoluminiscence Response of an Alloy Quaternary lonic Crystal Exposed to High Energy Radiation}

Exposed to Gamma Rays for Dosimetric Use.” Journal of Chemistry and Chemical Engineering 6 (12): 1093-8.

[6] Rubio, J. O. 1991. "Doubly-valent Rare-Earth Ions in Halide Crystals." Journal of Physics and Chemistry of Solids 52 (1): 101-74.

[7] Moroyoqui-Estrella, G., Perez-Salas, R., and Rodríguez-Mijangos, R. 2013. “A Generalized Rule of
Average for Glow Peak Temperature of Ternary Alkali Halide Systems." Revista Mexicana de Física 57 (2): 154-7.

[8] Moroyoqui-Estrella, G., Rodríguez-Mijangos, R. Pérez-Salas, R., and Rodríguez, A. 2013. "Thermal Properties of High Order Crystalline Dielectric Mixtures." Revista Mexicana de Física 59 (1): 16-9. 